\title{
The Effect of Standard Suction Training by Group Method Education on Nurses' Performance in Critical Care Unit
}

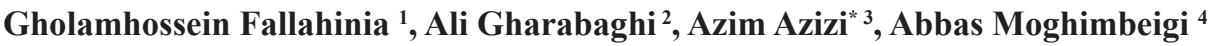

1. Instructor, Department of Medical Surgery, Chronic Diseases (Home Care) Research Centre, School of Nursing and Midwifery, Hamadan University of Medical Sciences, Hamadan, Iran

2. Critical Care Nursing Student (MSc), Student Research Committee, School of Nursing and Midwifery, Hamadan University of Medical Sciences, Hamadan, Iran

3. Assistant Professor, Chronic Diseases (Home Care) Research Centre, Malayer School of Nursing, Hamadan University of Medical Sciences, Hamadan, Iran

4. Professor, Department of Biostatistics, Hamadan University of Medical Sciences, Hamadan, Iran

\begin{tabular}{|c|c|}
\hline Article Info & Abstract \\
\hline $\begin{array}{lr}\text { Received: } & 2017 / 09 / 21 \\
\text { Accepted: } & 2018 / 01 / 16 \\
\text { Published Online } & 2018 / 03 / 16\end{array}$ & $\begin{array}{l}\text { Introduction: Nursing interventions have a direct impact on patients' clinical } \\
\text { status. Nurses should be aware of the dangers of intubation tube suction and have } \\
\text { continuous training in this field. The aim of this study was to determine the effect } \\
\text { of education standard suction with small group on nurses' performance in intensive } \\
\text { care unit. }\end{array}$ \\
\hline
\end{tabular}

DOI:

10.30699/sjhnmf.26.3.154

Methods : This was a quasi-experimental study which was conducted before and after intervention in 2017 . The statistical population included 40 nurses working in the intensive care unit who were selected by convenience sampling. First, nurses'

Original Article

Use your device to scan and read the article online

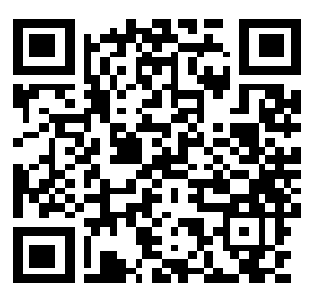
performance in the suction process was evaluated by a standard checklist in an imperceptible way. Then, standard suction training was performed in three sessions of one hour using the small group discussion method. One month after training, nurses' suction function was evaluated again and analyzed by SPSS16.

Results: The mean of standard suction score after training $(64.4 \pm 3.7)$ was significantly different from the pre-training $(58.5 \pm 3.5)$, which is statistically significant (t-test) $(P<0 / 05)$.

Conclusion: The results showed that nurses' function in the area of suction needs more attention. In order to improve the clinical performance of nurses, the use of training in small groups is useful. Therefore, training courses in small groups should be offered in the form of in-service nursing courses.

Keywords: Suction, Discussion in small groups, Intensive care unit, Nurses' function

Azim Azizi, Assistant Professor, Chronic Diseases (Home Care) Research Centre, Malayer School of

Corresponding Information Nursing, Hamadan University of Medical Sciences, Hamadan, Iran Email:azimazizi1360@gmail.com

Copyright $(C$ 2018, Sci J Hamadan Nurs Midwifery Fac. This is an open-access article distributed under the terms of the Creative Commons Attribution-noncommercial 4.0 International License which permits copy and redistribute the material just in noncommercial usages, provided the original work is properly cited.

How to Cite This Article:

Fallahinia G, Gharabaghi A, Azizi A, Moghimbeigi A. The Effect of Standard Suction Training by Group Method Education on Nurses' Performance in Critical Care Unit . Sci J Hamadan Nurs Midwifery Fac. 2018; 26 (3): 145-154 
مجله علمى دانشكده يرستارى و مامايى همدان - شايا الكترونيك: 19

مقاله يثوهشى

بررسى تأثير آموزش ساكشن استاندارد بهروش بحث در گروههاى كوجى پبر عملكرد يرستاران در

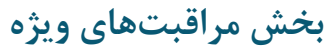

\section{غلامحسين فلاحىنيا'، على قراباغى '، عظيم عزيزى" "،عباس مقيمبيكى "}

مربى، گروه داخلى و جراحى، مركز تحقيقات بيمارىهاى مزمن (مراقبت در منزل)، دانشكدة يرستارى مامايى، دانشگاه علوم يزشكى همدان، همدان، ايران

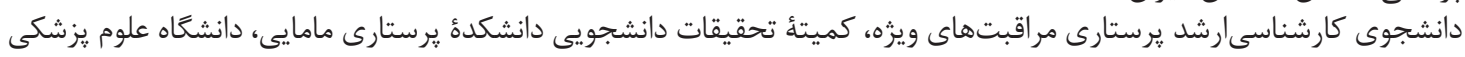
همدان، همدان، ايران

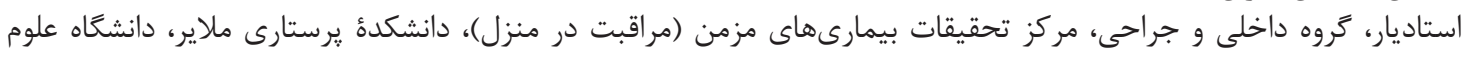

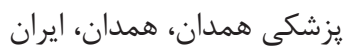
استاد، كروه آمار زيستى، دمان، انشكده بهداشت، دانشعاه علوم يزشكى همدان، همدان، ايران

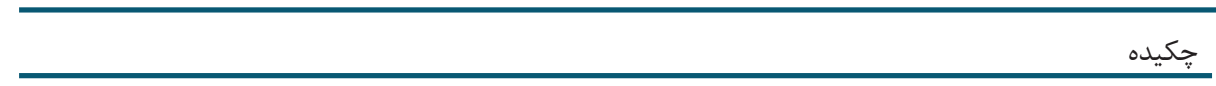

مقدمه: مداخلات ثرستارى در وضعيت بالينى بيماران تأثير مستقيم دارد. ازاينرو پرستاران بايد از مخاطرات

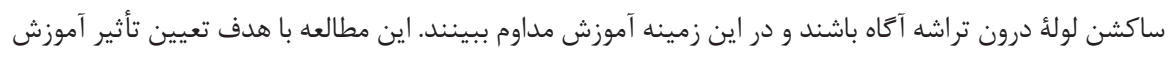

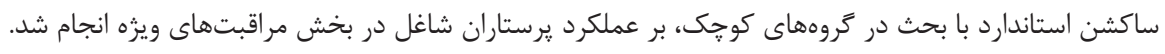

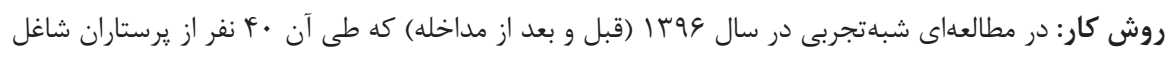

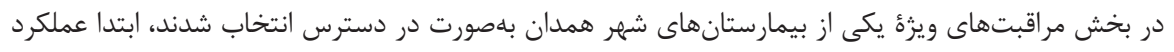

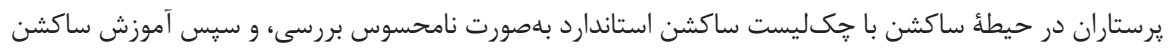

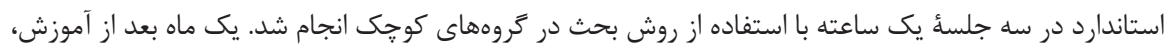

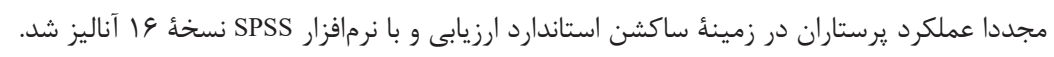

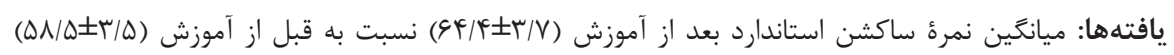

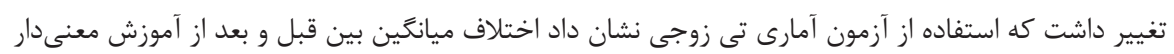

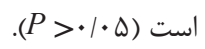

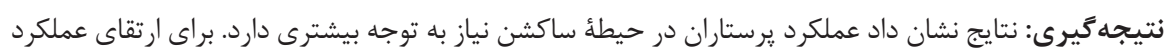

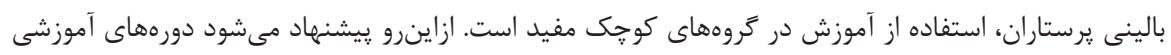

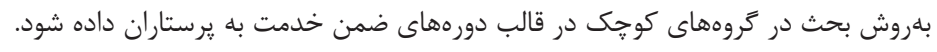
وازههاى كليدى: ساكشن، بحث در تروههاى كوجى، بخش مراقبتهاى ويزه، عملكرد يرستاران

\begin{tabular}{|c|c|}
\hline \multicolumn{2}{|c|}{ اطلاعات مقاله } \\
\hline |r৭८/я/ル. & تاريخ وصول: \\
\hline$|r q \& /| \cdot / r q$ & تاريخ يذيرش: \\
\hline$|r q s /| r / T \Delta$ & انتشار آنلاين: \\
\hline & نويسندهُمس \\
\hline & كزيزى \\
\hline
\end{tabular}

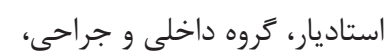
مركز تحقيقات بيمارىهاى مزمن

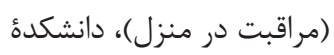
يرستارى ملاير، دانشخاه علوم يزشكى همدان، همدان، ايران

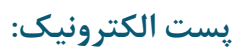
azimazizi1360@gmail.cm

$$
\text { به ֶنومونى منجر شود [F] }
$$

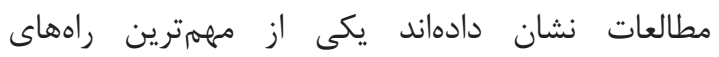

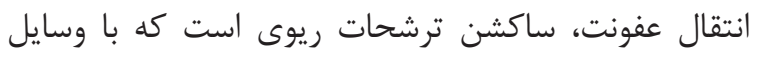

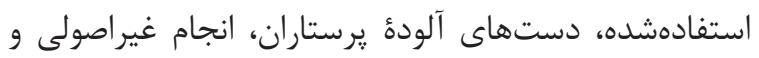

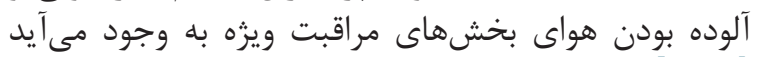

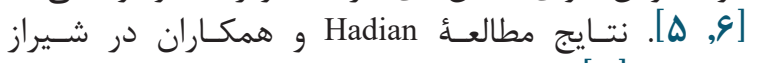

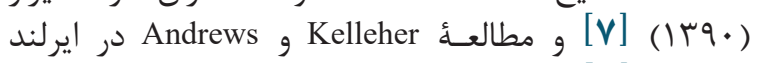

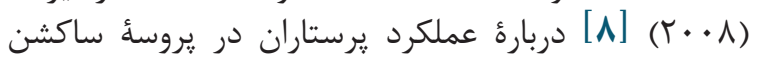

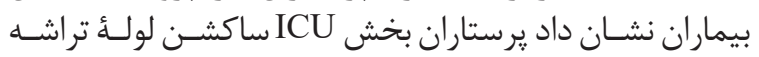

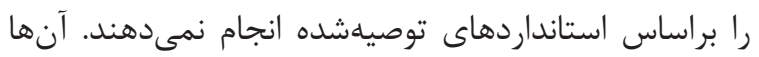

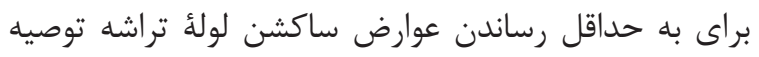

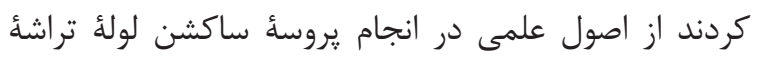

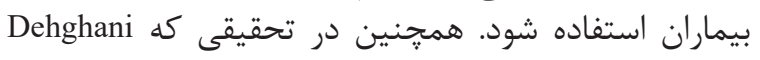

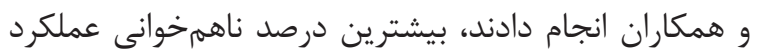

دوره צr شماره r - مرداد و شهريور
مقدمه

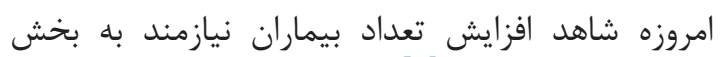

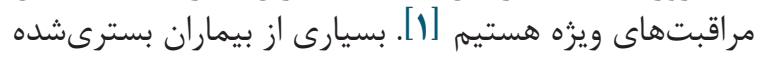

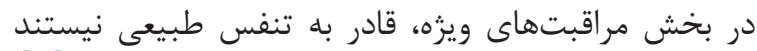

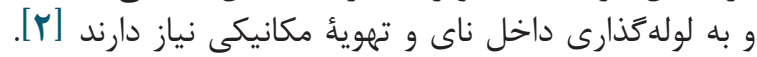

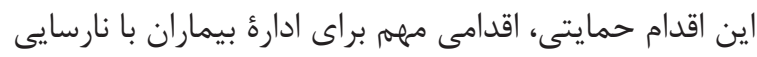

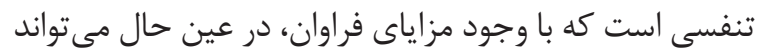

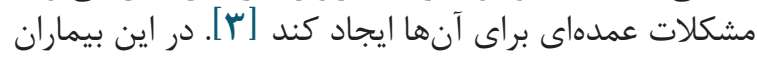

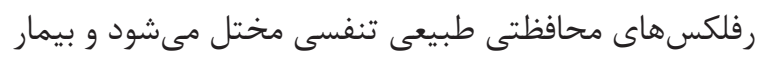

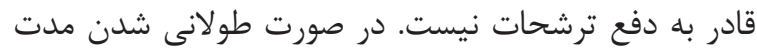

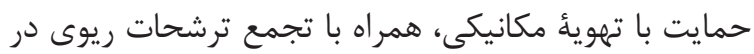

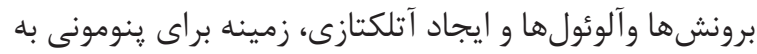

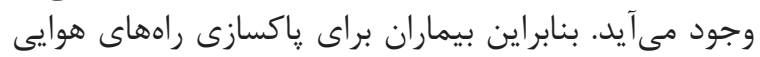

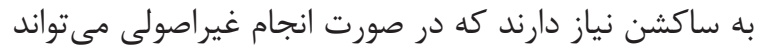

مجله علمى دانشكده يرستارى و مامايى همدان 


\section{روش كار}

اين مطالعأ شباهتجربى يك گروهى قبل و بعد، به مدت 9

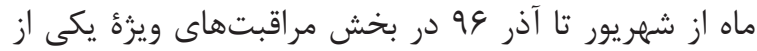

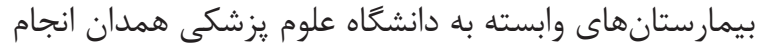

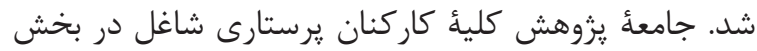

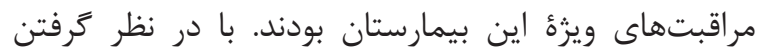

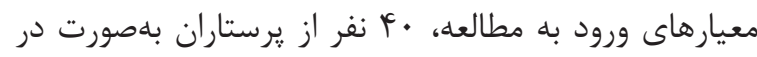

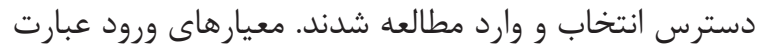

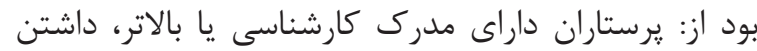

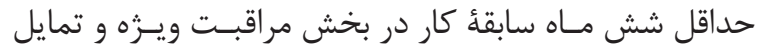

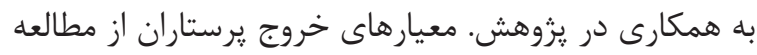

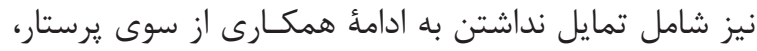

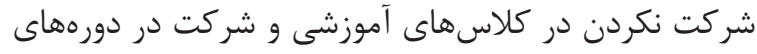

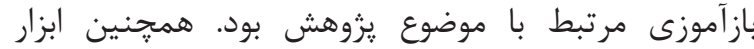

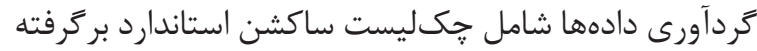

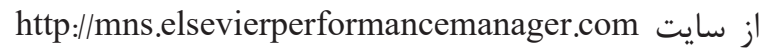

مى شد [11].

براى تعيين روايى صورى و محتوايى جكىليستها، از إز

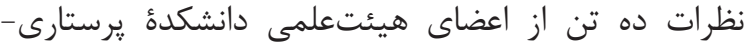

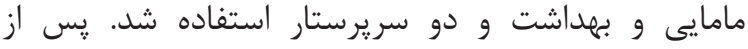

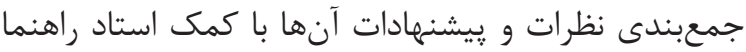

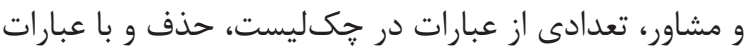

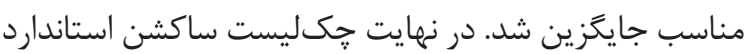

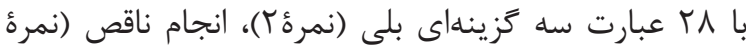

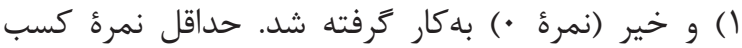

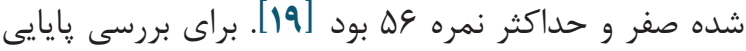

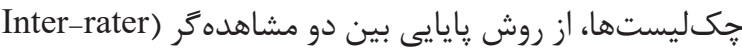
(reliability

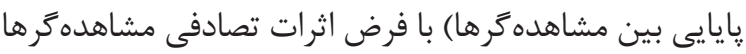

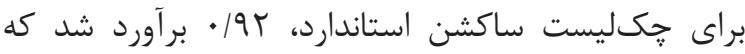
نشان مىدهد يايايى مناسبى دارد.

روش كار به اين صورت بود كه قبل از مداخله آموزش

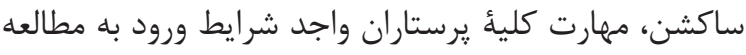

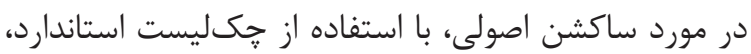

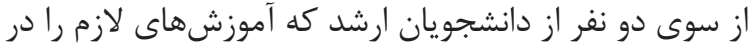

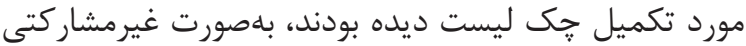
و نامحسوس، مشاهده و تكميل شد. جدئ

ترستاران براساس شيفتهاى كارى به له كروه 1 نفره

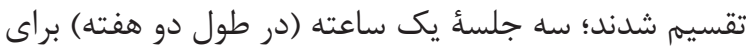

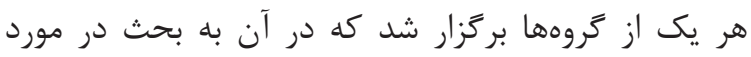

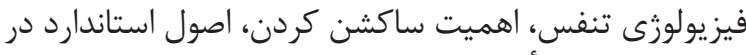

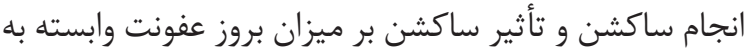

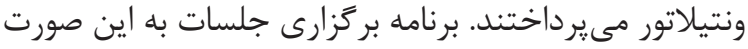

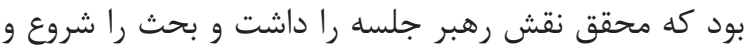

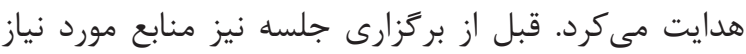

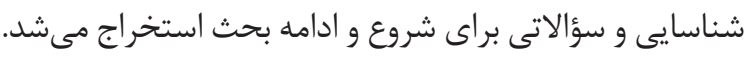

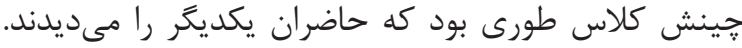
از شركتكنندكان درخواست شده بود بود قبل از جلسه برد درباره
يرستاران با استانداردها، مربوط به يروسةٔ ساكشن بوده است

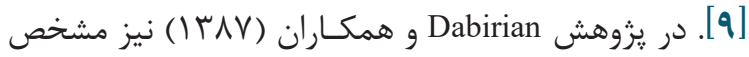

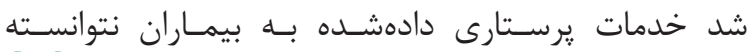

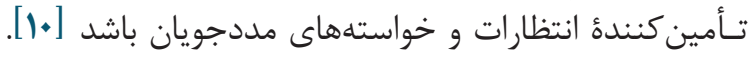

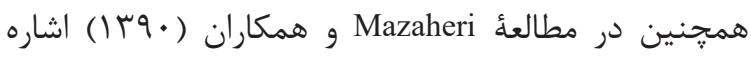

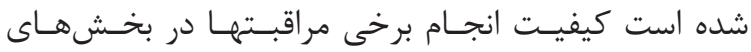

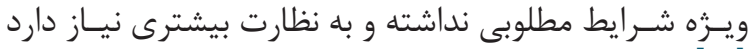

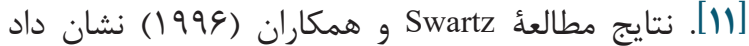

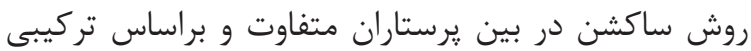

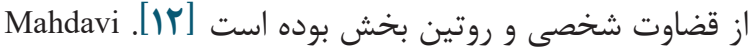

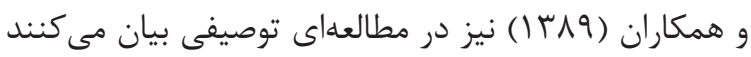

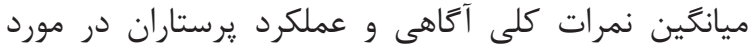
ساكشن اصولى از استانداردهاى علمى فاصى فاصله دادين فاد. بنابراين

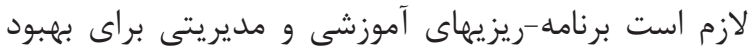

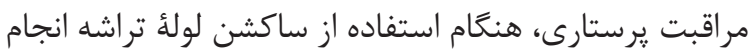
شود [11اق].

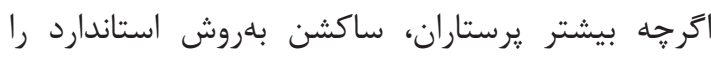

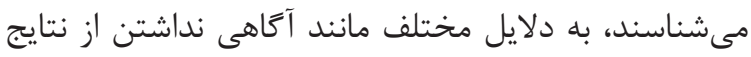

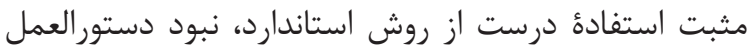

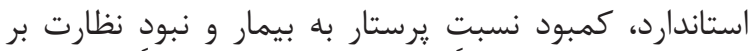

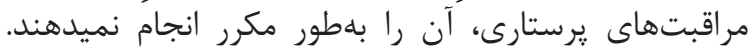

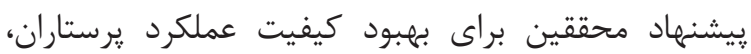

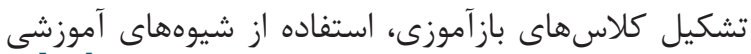

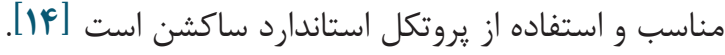

روش بحث گروهى يكى از روشهاى مؤثر آموزشى است؛

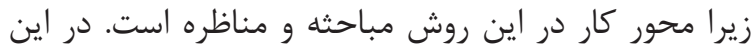

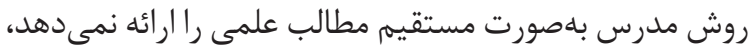

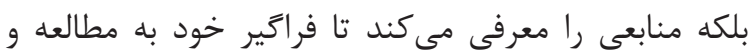

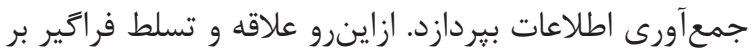

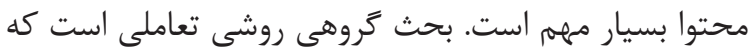

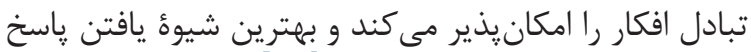

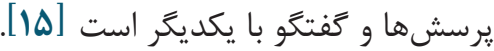

يكى از بهترين روشهاى آموزش بهويزه براى افرادى كه

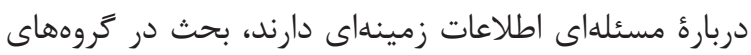

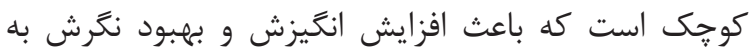

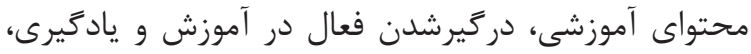

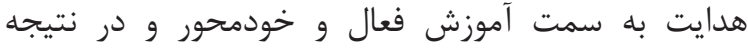

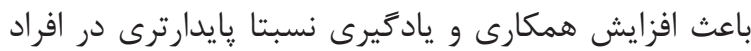

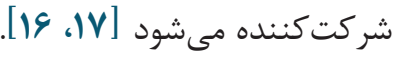

با توجه به نتايج مطالعات ريشين كه نشاندهنده يايين

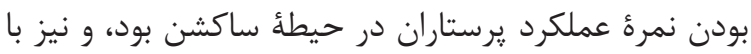

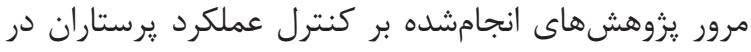

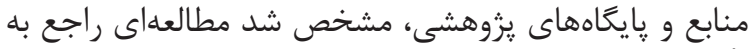

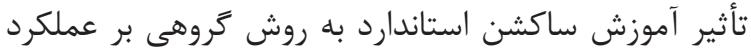

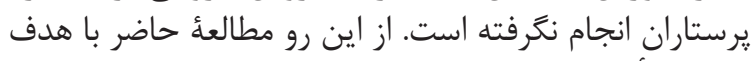

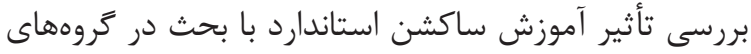

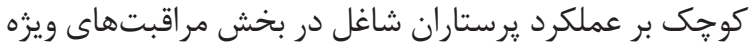
انجام شد. 
ميانكين، انحرافمعيار و تى زوجى آناليز و سطح معنى دارى (ه)

\section{يافتهها}

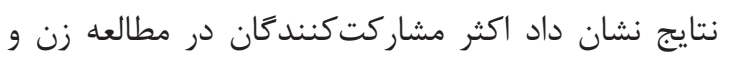

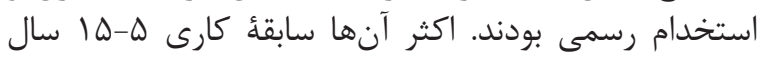

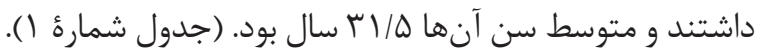

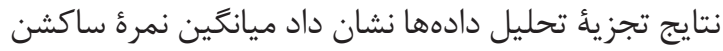

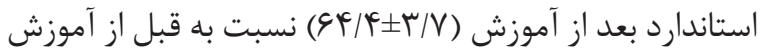

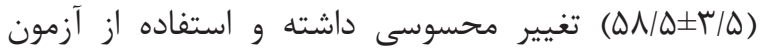

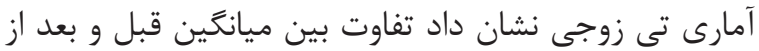

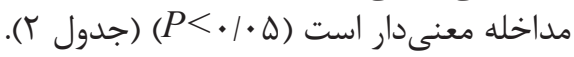

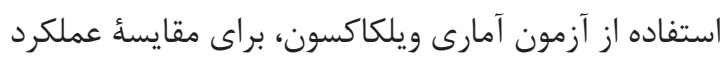

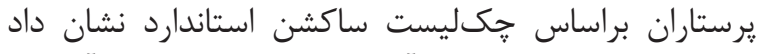

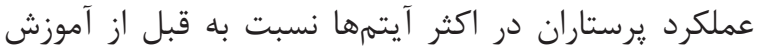

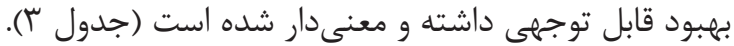

موضوع مطالعه داشته باشند و در شروع هر كلاس مدت زماف زمان

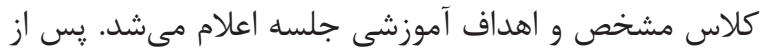

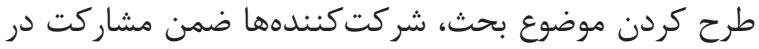

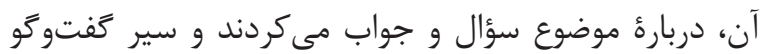

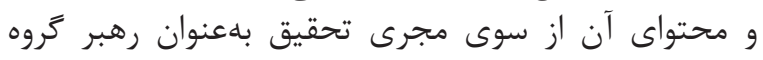

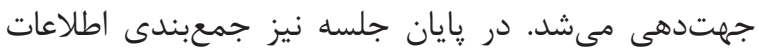

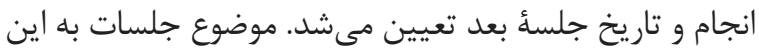

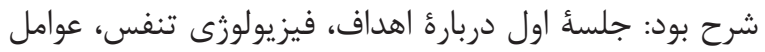

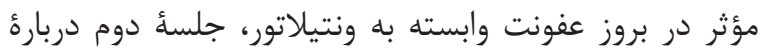

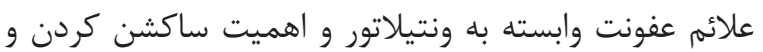
موضوع جلسئ سوم اصول استاندارد در انجام ساكشن ونت و تأثني

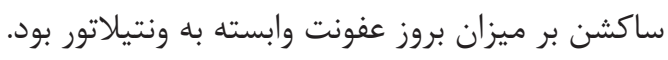

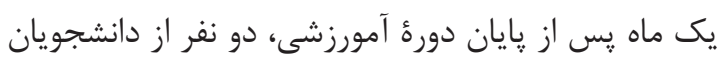

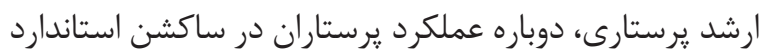

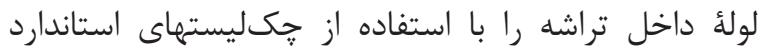

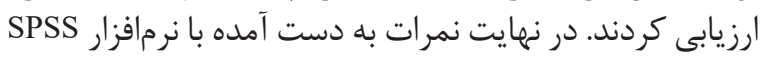

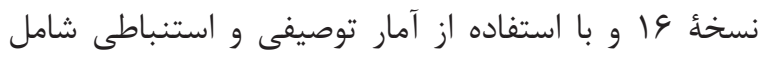
جدول شمارة ا. متغيرهاى دموكر افيك شركت كنيندكان در مطالعه

\begin{tabular}{|c|c|c|c|}
\hline درصد & تعداد(n) & & متغيير \\
\hline$\% \wedge v / \Delta$ & ra & زن & \multirow[b]{2}{*}{ 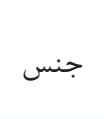 } \\
\hline$\% / r / \Delta$ & $\Delta$ & مرد & \\
\hline$\% \Delta \Delta$ & rr & رسمى & \multirow{4}{*}{ استخدام } \\
\hline$\%$ r. & $\wedge$ & بيمانى & \\
\hline$\% 10$ & 4 & طرحى & \\
\hline$\%$. & r & شركتى & \\
\hline$\%$ ra & 1. & كمتر از ه سال & \multirow{5}{*}{ سابقة كار } \\
\hline$\%$ \%r/Q & r & $\Delta-1$. & \\
\hline$\% r r / \Delta$ & ir & $1 \cdot-10$ & \\
\hline$\% v / \Delta$ & r & $\mid Q-r$. & \\
\hline$\%$ \%/D & 1 & بالاى · r ب & \\
\hline \multicolumn{4}{|c|}{ انحرافمعيار و ميانكين } \\
\hline$r \mid / \Delta \pm \Delta / F$ & r. & & سن \\
\hline
\end{tabular}

جدول شمارهُ r. مقايسُٔ ميانكين و انحرافمعيار نمره آموزش ساكشن استاندارد بر عملكرد يرستاران در بخش مراقبتهاى ويزه

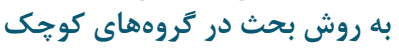

\begin{tabular}{|c|c|c|c|c|}
\hline سطح معنى دارى (P Value) & Df & مقدار t & ميانكين \ انحرافمعيار & آموزش ساكشن استاندارد \\
\hline \multirow{2}{*}{$(P<\cdot / \cdot \Delta)$} & \multirow{2}{*}{ rq } & \multirow{2}{*}{$\mid T / \cdot \Delta V$} & $\Delta \Lambda / \Delta \pm r / \Delta$ & قبل \\
\hline & & & $G F / F \pm r / V$ & بعد \\
\hline
\end{tabular}




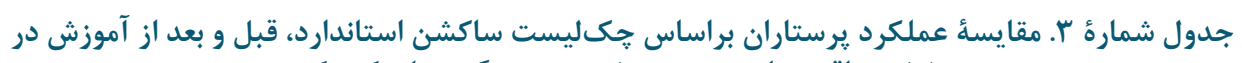

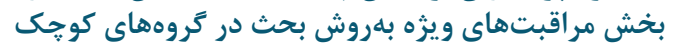

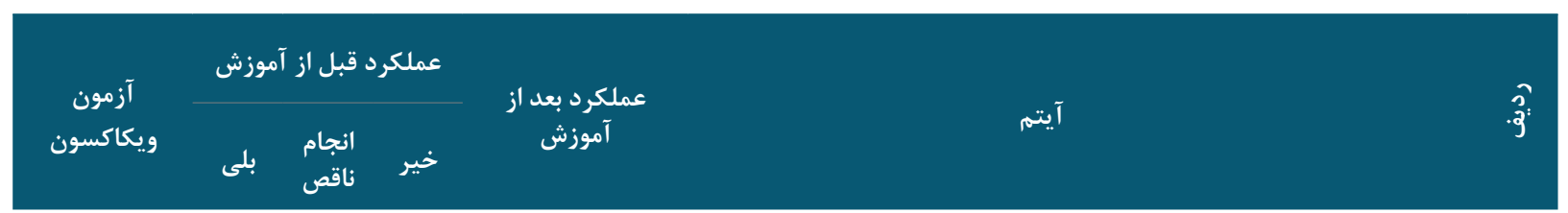

\begin{tabular}{|c|c|c|c|c|c|c|c|}
\hline$Z=-1 / \lambda \vee \Delta$ & r & 1 & 10 & 11 & 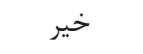 & \multirow{3}{*}{ شستشوى دست را با روش صحيح انجام مىدهد } & \multirow{3}{*}{1} \\
\hline \multirow[b]{2}{*}{$P=\cdot 1 \cdot 9$} & 1 & 11 & · & it & 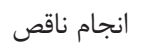 & & \\
\hline & 1. & . & - & 1. & 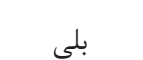 & & \\
\hline \multirow[t]{2}{*}{$Z=-r / \varphi \uparrow$} & · & · & IV & IV & خير & \multirow{3}{*}{ علائم مشكلات راه هوايى و كاهش اكسيرناسيون را ارزيابى مى كند } & \multirow{3}{*}{ r } \\
\hline & · & lf & r & IV & 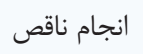 & & \\
\hline$P=\cdot / \cdot 1$ & r & r & r & 9 & بلى & & \\
\hline \multirow{2}{*}{$Z=-r / I V T$} & $\cdot$ & · & rF & rF & خير & \multirow{3}{*}{ در صورت هوشيار بودن بيمار روش كار را براى او توضيح مى دهد } & \multirow{3}{*}{ r } \\
\hline & · & 1. & r & if & انجام ناقص & & \\
\hline$P=\cdot / \cdot r$ & . & · & $r$ & r & 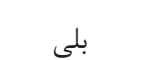 & & \\
\hline \multirow[t]{2}{*}{$Z=-r / \xi T r$} & $\cdot$ & $\cdot$ & $r \cdot$ & r. & خير & \multirow{3}{*}{ به بيمار براى گرفتن يوزشين مناسب كمك مى كند } & \multirow{3}{*}{ r } \\
\hline & . & If & r & 19 & 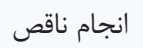 & & \\
\hline$P=\cdot / \cdot r$ & 1 & r & • & f & 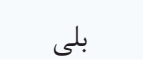 & & \\
\hline \multirow[t]{2}{*}{$Z=-r / \Gamma \Delta$} & . & . & 19 & 19 & خير & \multirow{3}{*}{ عمق مناسب را براى داخل كردن سوند ساكشن تعيين مى كند } & \multirow{3}{*}{$a$} \\
\hline & . & 11 & 1 & ir & انجام ناقص & & \\
\hline$P=\cdot / \cdot 1$ & $r$ & . & 9 & 9 & بلى & & \\
\hline \multirow{3}{*}{$\begin{array}{c}Z=-r \\
P=\cdot / \cdot r\end{array}$} & . & $\cdot$ & . & $\cdot$ & 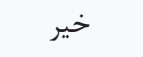 & \multirow{3}{*}{ دستخاه را روشن مى كند و فشار آن را كمتر از • له ميلىمتر جيوه تنظيم } & \multirow{3}{*}{9} \\
\hline & . & . & . & $\cdot$ & 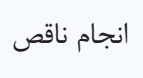 & & \\
\hline & re & i & - & $r$. & 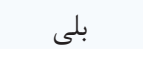 & & \\
\hline \multirow[t]{2}{*}{$Z=-r / \wedge ৭ \Delta$} & . & . & $r \cdot$ & r. & خير & \multirow{3}{*}{ فشار منفى دستگاه را با بستن انتهاى لولؤ ساكشن جك مىكند } & \multirow{3}{*}{$v$} \\
\hline & $\cdot$ & 11 & $r$ & 14 & انجام ناقص & & \\
\hline$P=\cdot / \cdots q$ & 1 & $\cdot$ & $\Delta$ & 9 & بلى & & \\
\hline \multirow{3}{*}{$\begin{array}{l}Z=-r / \& \varphi \& \\
P=\cdot / \wedge\end{array}$} & . & . & $r \Delta$ & $r \omega$ & 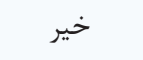 & \multirow{3}{*}{ از تكنيك آسيتيك براى باز كردن ست استريل كتتر بر روى سطح تميز } & \multirow{3}{*}{$\wedge$} \\
\hline & . & $\Lambda$ & V & 10 & 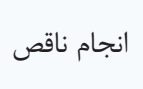 & & \\
\hline & . & $\cdot$ & . & . & بلى & & \\
\hline \multirow[t]{2}{*}{$Z=-|/ F| f$} & . & . & . & $\cdot$ & خير & & \\
\hline & . & . & 11 & 11 & انجام ناقص & انتهاى كتتر را براى اتصال به دستخاه باز مى كند & 9 \\
\hline$P=\cdot / 1$ & tr & r & · & rq & 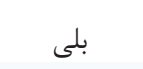 & & \\
\hline$Z=-|/ \uparrow| \uparrow$ & . & . & . & · & 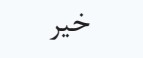 & & \\
\hline$P$ & . & . & If & $1 f$ & 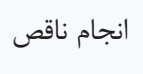 & نرمال سالين يا آب استريل را براى شستشوى كتتر بعد از انجام ساكشن & 1 . \\
\hline & · & tr & $r$ & rq & 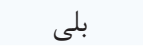 & & \\
\hline
\end{tabular}




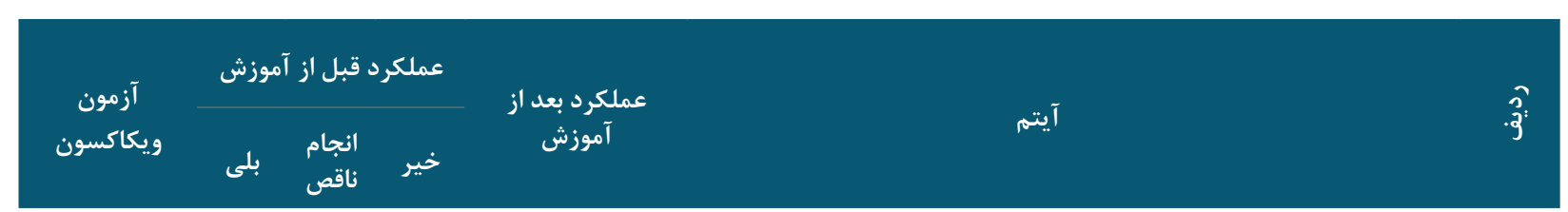

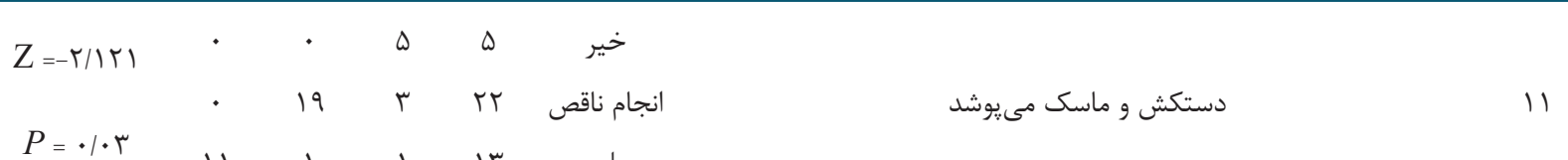

$$
\begin{aligned}
& \begin{array}{llllll} 
& P=\cdot / 11 & 1 & 1 & 1
\end{array}
\end{aligned}
$$

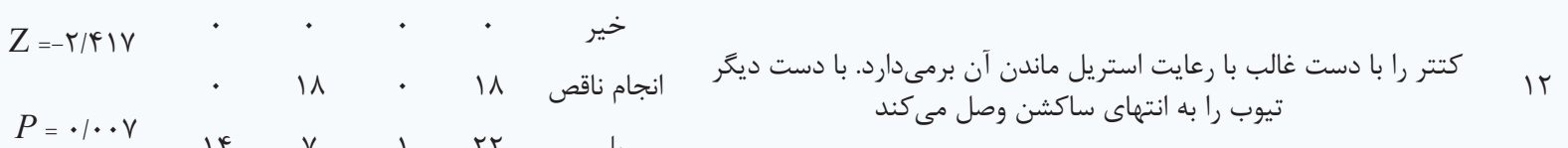

$$
\begin{aligned}
& P=\cdot / \cdot V \quad \text { If } \quad V \quad 1 \quad \text { r } \quad \text { r }
\end{aligned}
$$

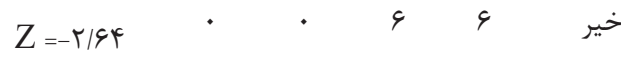

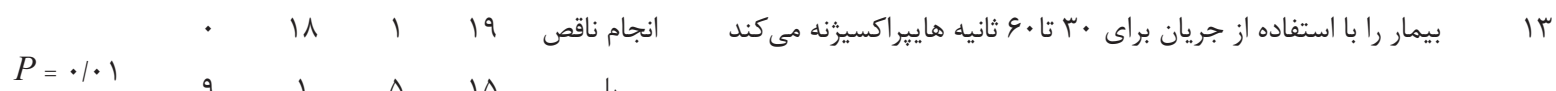

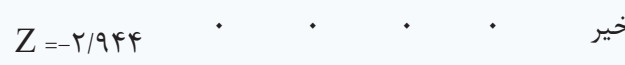

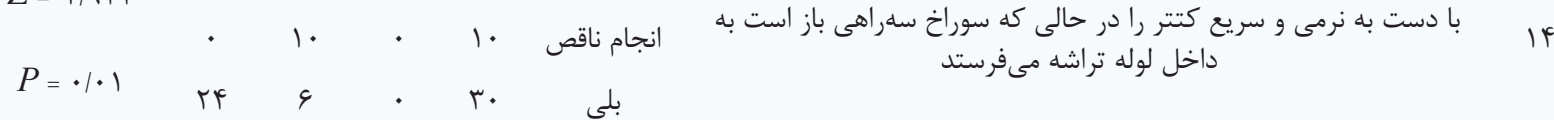

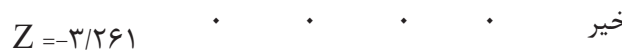

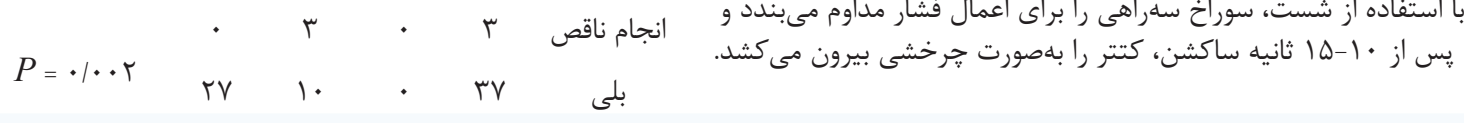

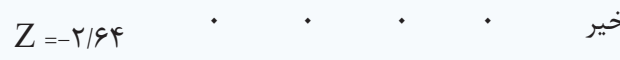

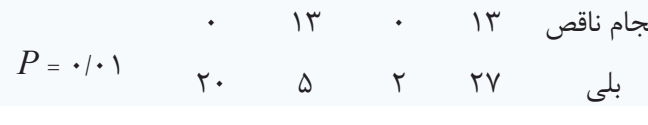

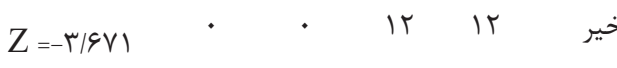

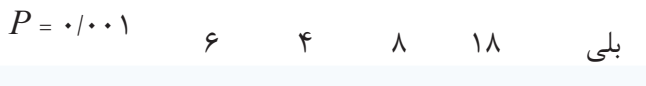

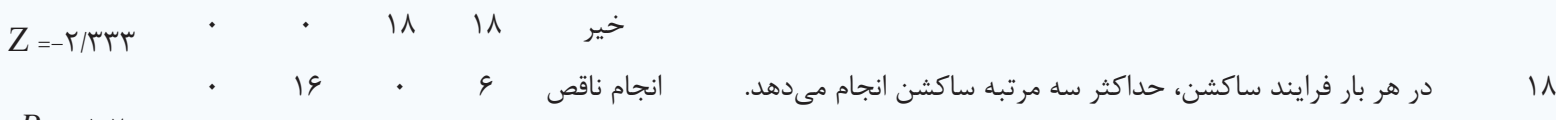

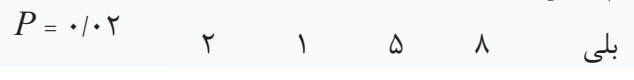

$$
\begin{aligned}
& Z=-r / 949 \text { خ }
\end{aligned}
$$

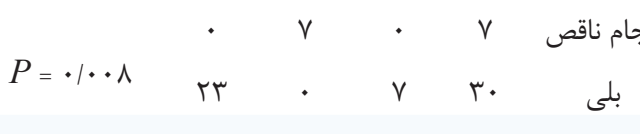

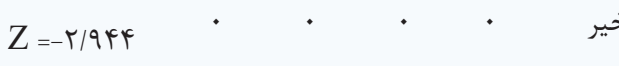

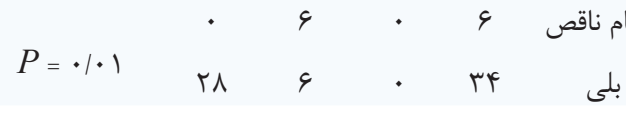

$$
\begin{aligned}
& Z=-Y / I V T \cdot 10 \quad \cdot 10 \quad 10 \quad 10
\end{aligned}
$$

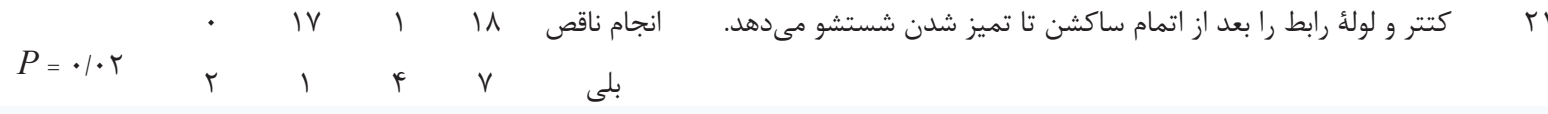

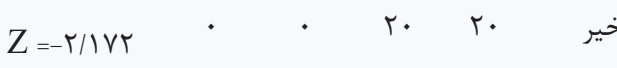

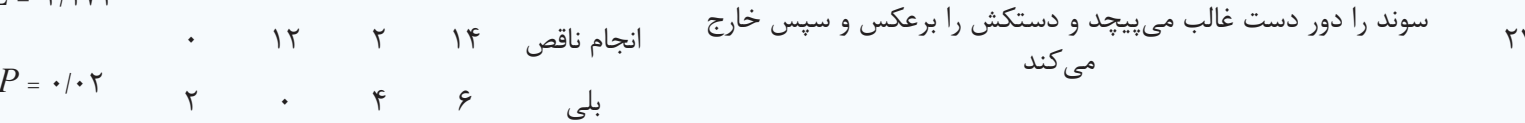




\begin{tabular}{|c|c|c|c|c|c|c|}
\hline \multirow{2}{*}{ ويكاكسون } & \multicolumn{3}{|c|}{ 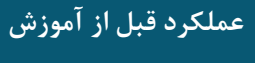 } & \multirow{2}{*}{ عملكرد بعد از } & \multirow{2}{*}{ آيته } & \multirow{2}{*}{$\hat{3}$} \\
\hline & 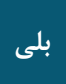 & انجام & 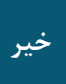 & & & \\
\hline \multirow{2}{*}{$\mathrm{Z}=\cdot / \cdots$} & $\cdot$ & $\cdot$ & $\cdot$ & خير & & \\
\hline & • & · & • & 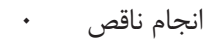 & در پايان ساكشن را خاموش مى كند. & r \\
\hline$P=1$ & r. & $\cdot$ & • & f. $\quad$ بلى & & \\
\hline \multirow{3}{*}{$\begin{array}{c}\mathrm{Z}=\cdot 1 \cdots \\
P=1\end{array}$} & $\cdot$ & $\cdot$ & $\cdot$ & 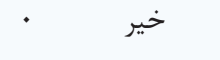 & & \\
\hline & · & $\cdot$ & $\cdot$ & 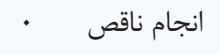 & از تنظيم ميزان اكسيزن دستگاه به مقدار قبل از ساكشن مطمئن مىشود. & TY \\
\hline & r. & · & · & f. & & \\
\hline \multirow[t]{2}{*}{$Z=-r / r \Delta$} & $\cdot$ & $\cdot$ & r & خير & & \\
\hline & $\cdot$ & r & $\cdot$ & 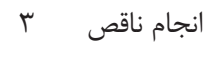 & هر گَونه تغيير در رنَ، غلظت و حجم را گَزارش مىدهد. & $r \omega$ \\
\hline$P=\cdot / \cdot 1$ & TV & 1 & 4 & لى & & \\
\hline \multirow[t]{2}{*}{$Z=r$} & • & · & $\cdot$ & خير & & \\
\hline & $\cdot$ & $1 \cdot$ & $\cdot$ & 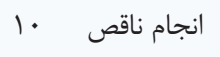 & تجهيزات استفادهشه را دفع مى كند & rq \\
\hline$P=\cdot / \cdot \uparrow$ & rq & r & $\cdot$ & $r \cdot$ & & \\
\hline \multirow[t]{2}{*}{$Z=-1 \mu / 1 \mathrm{~V}}$. & · & · & \& & خير & & \\
\hline & • & $\Delta$ & 1 & انجام ناقص & بهداشت دستها را اجرا مى كند & TV \\
\hline$P=\cdot / \cdot r$ & 11 & $r$ & $\Lambda$ & بلى & & \\
\hline \multirow{2}{*}{$Z=-r / V$} & - & · & 1 & 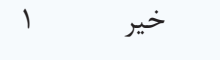 & & \\
\hline & $\cdot$ & $r \Lambda$ & $\cdot$ & 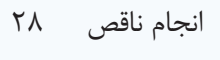 & يروسه را در يرونده ثبت مى كند. & rA \\
\hline$P=\cdot / \cdot r$ & 4 & r & r & بلى & & \\
\hline
\end{tabular}

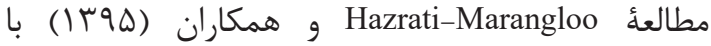
هدف بررسى ميزان اثربخشى آموزش در كروهارهاى كورجى

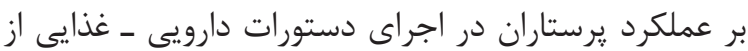

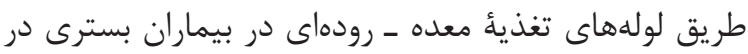

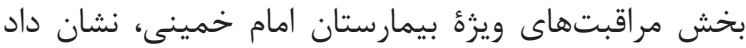

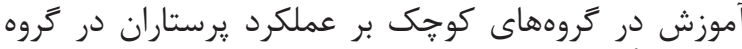

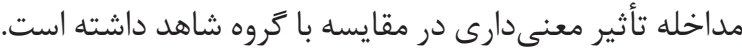

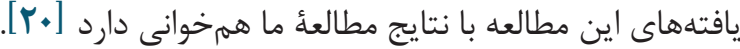
Ghotbi

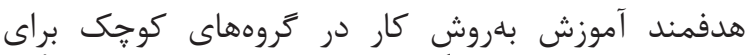

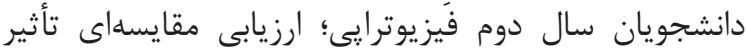

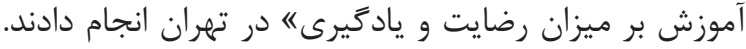

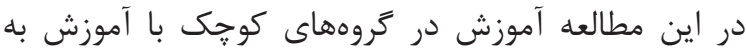

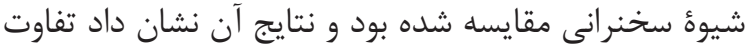

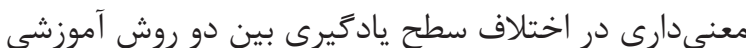

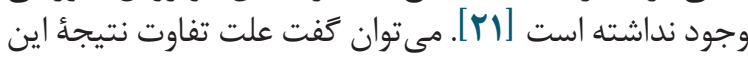

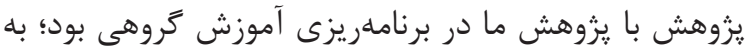

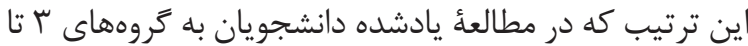

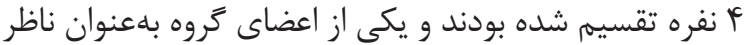

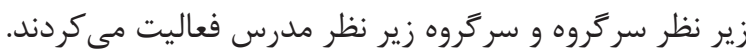

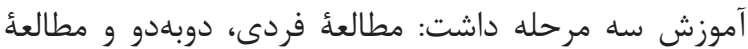

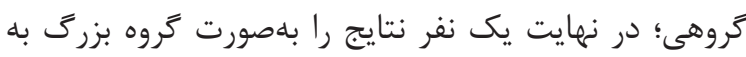
اين مطالعه با هدف ارزيابى تأثير آموزش ساكشن

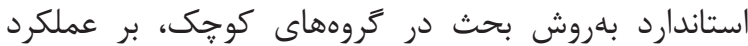

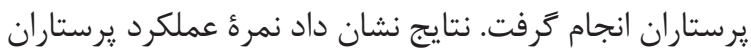

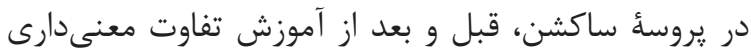

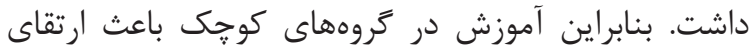

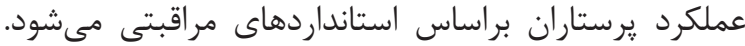

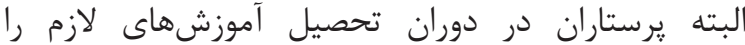

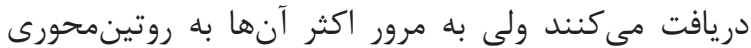

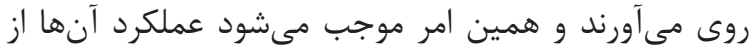

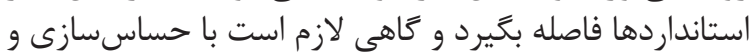

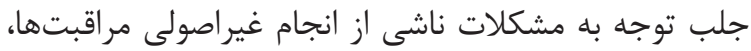

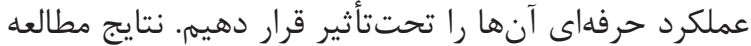

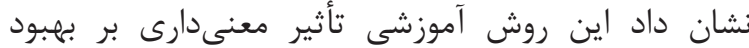

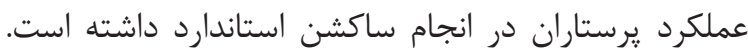

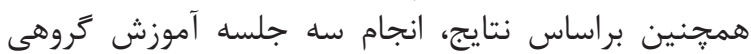

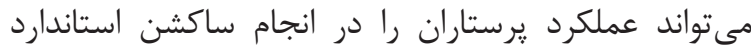

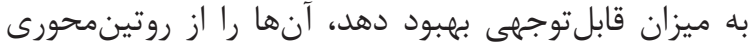

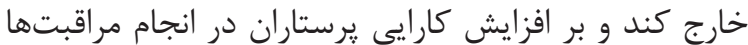

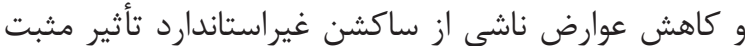

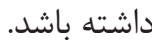




\section{نتيجه گَيرى}

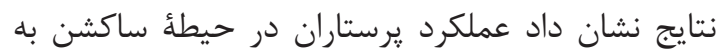

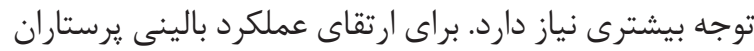

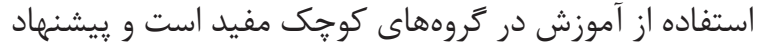

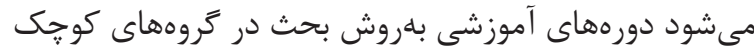

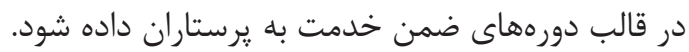
سياسگزارى

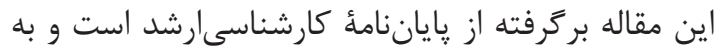

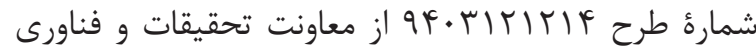

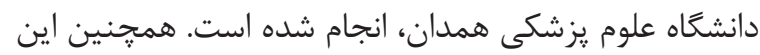

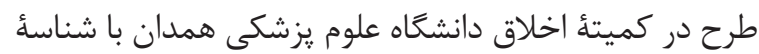

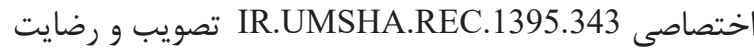

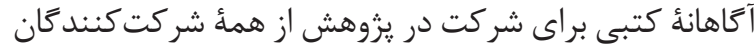

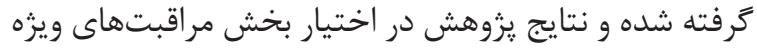

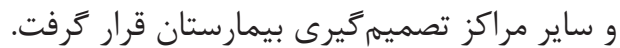

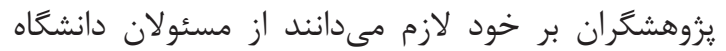

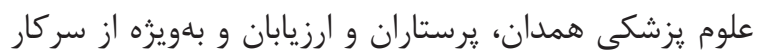
خانم مليحه سراج تشكر نمايند. تعارض منافع بين نويسندگان هيجزَّه تعارضى در منافع وجود ندارد.
كل گروهها ارائه مى داد. نتايج نشان داد در دو روش سخنرانى اختى

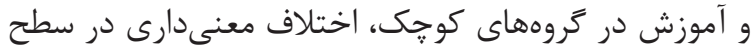

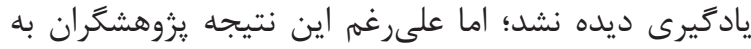

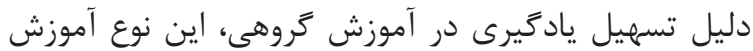
را توصيه كردند.

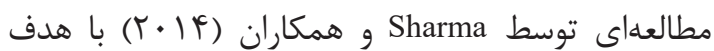
بررسى تأثير آموزش عملى :روتكل توسط ساكشن داخل تراشه بر

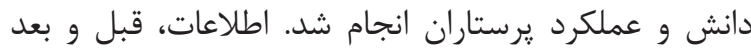

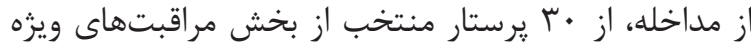

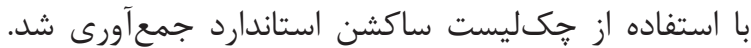

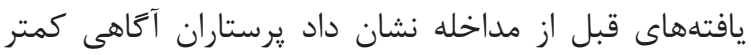

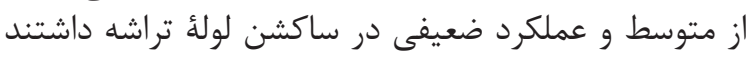

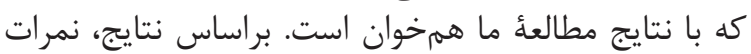

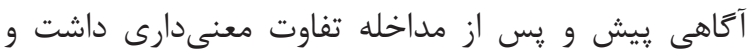

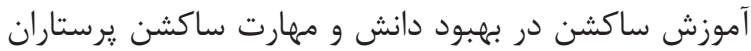

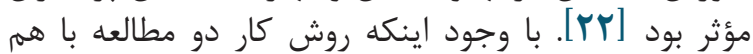

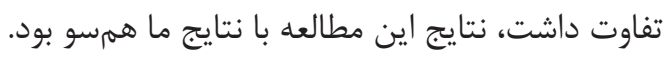

با توجه به روتينمحورى در عملكرد يرستاران، توصيه

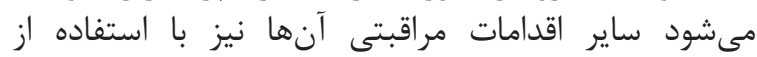

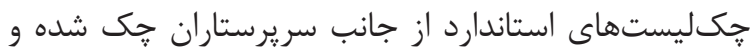

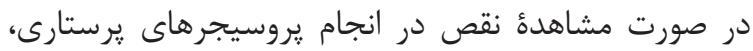

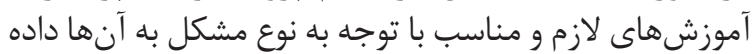

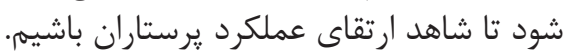

\section{References}

1. McConnell KJ, Richards CF, Daya M, Bernell SL, Weathers CC, Lowe RA. Effect of increased ICU capacity on emergency department length of stay and ambulance diversion. Annals of emergency medicine. 2005;45(5):471-8.https://doi. org/10.1016/j.annemergmed.2004.10.032

2. da Silva Naue W, da Silva ACT, Güntzel AM, Condessa RL, de Oliveira RP, Vieira SRR. Increasing pressure support does not enhance secretion clearance if applied during manual chest wall vibration in intubated patients: a randomised trial. Journal of physiotherapy. 2011;57(1):21-6. https://doi.org/10.1016/S1836-9553(11)70003-0

3. Firouzian A, Baradari AG, Kiabi FH. The Importance of Oral Hygiene in Prevention of Ventilator-Associated Pneumonia (VAP): A Literature Review. International Journal of Caring Sciences. 2014;7(1):12.

4. Kozier B. Fundamentals of nursing: concepts, process and practice: Pearson Education; 2008.

5. Volpe MS, Adams AB, Amato MB, Marini JJ. Ventilation patterns influence airway secretion movement. Respiratory care. 2008;53(10):128794.

6. Dias CM, Siqueira TM, Faccio TR, Gontijo
LC, Salge JAdSB, Volpe MS. Bronchial hygiene technique with manual hyperinflation and thoracic compression: effectiveness and safety. Revista Brasileira de terapia intensiva. 2011;23(2):190-8.https://doi.org/10.1590/S0103507X2011000200012

7. Hadian Shirazi Z, Kargar M, Edraki M, Ghaem $\mathrm{H}$, Pishva N. The effect of instructing the principles of endotracheal tube suctioning on knowledge and performance of nursing staff working in neonatal intensive care units in shiraz university of medical sciences. Iranian Journal of Medical Education. 2010;9(4):365-70.

8. Kelleher S, Andrews T. An observational study on the open-system endotracheal suctioning practices of critical care nurses. Journal of clinical nursing. 2008;17(3):360-9.https://doi. org/10.1111/j.1365-2702.2007.01990.x

9. Dehghani K, Nasiriani K, Mousavi T. Investigating Intensive Care Unit Nurses' Performance and its Adjusting with Standard. SSU_Journals. 2014;21(6):808-15.

10. Dabirian A, Zolfaghari H, Saidi ZA, Alavi-Majd $\mathrm{H}$. Views of AIDS patients regarding nursing care quality in healthcare centers affiliated to Shaheed 
Beheshti and Tehran Universities of Medical Sciences. Journal of Shahid Beheshti School of Nursing \& Midwifery. 2008;18(61).

11. Mazaheri E, Seyed Javadi M, Mohammadi R, Pour S, Taghi M, Kazem Zadeh R. Performance of the nursing staff in taking care of endotracheal tubes in patients with mechanical ventilation. Journal of Health And Care. 2011;13(2):1-8.

12. Swartz K, Noonan DM, Edwards-Beckett J. A national survey of endotracheal suctioning techniques in the pediatric population. Heart \& Lung: The Journal of Acute and Critical Care. 1996;25(1):52-60.https://doi.org/10.1016/ S0147-9563(96)80013-6

13. Mahdavi S, Raigani AA, Baazdaar S. A Survey on the Knowledge and Practice of Nurses about Tracheal Suction Nursing Care in Specialized Hospitals of Kermanshah, 2010

14. Çelik SS, Elbas NÖ. The standard of suction for patients undergoing endotracheal intubation. Intensive and Critical Care Nursing. 2000;16(3):191-8.https://doi.org/10.1054/ iccn.2000.1487

15. Annamalai N, Manivel R, Palanisamy R. Small group discussion: students perspectives. International Journal of Applied and Basic Medical Research. 2015;5(Suppl 1):S18.https://doi. org/10.4103/2229-516X.162257

16. Powell CK, Hill EG, Clancy DE. The relationship between health literacy and diabetes knowledge and readiness to take health actions. The diabetes educator. 2007;33(1):144-51.https://doi. org/10.1177/0145721706297452

17. Safari M, Shojaeezadeh D, Ghofrani F, Haidarnia A, Pakpour A. Theories, Models and methods in Health Education and Promotion. 1th edition ed. Tehran: Asare Sobhan Publications; 2009.

18. American Nursing Association. Check list of nursing practice 2017. Available from: http:// mns.elsevierperformancemanager.com.

19. Kunis KA, Puntillo KA. Ventilator-Associated Pneumonia in the ICU: Its pathophysiology, risk factors, and prevention. AJN The American Journal of Nursing. 2003;103(8):64AA-GG.

20. Hazrati-Marangloo A, Radfar M, Mohammadpour Y, Sheikhi N. The effectiveness of small group teaching on the nurses'performance of food-drug administration through enternal feeding tube in intensive care unit patients hospitalized in imam khomeini hospital in 2014. Journal of Urmia Nursing And Midwifery Faculty. 2016;14(2):128-35.

21. Ghotbi N, Shirazi M, Jalaei S, Bagheri H, Naghdi S, Mousavi S. The targeted implementation of teaching in small group discussion for secondyear students in physiotherapy:A comparative assessment of teaching effect on satisfaction and learning level. Journal of Modern Rehabilitation. 2011;5(3):60-6.

22. Sharma S, Sarin J, Kaur Bala G. Effectiveness of endotracheal suctioning protocol, In terms of knowledge and practices of nursing personnel. Nursing and Midwifery Research Journal. 2014;10(2):47-60 
